\title{
PENINGKATAN PROMOSI DAN PENGELOLA OBJEK WISATA MELALUI PELATIHAN GMB (GOOGLE MY BUSINESS) DI KAMPUNG WISATA SANJAI BUKITTINGGI
}

\author{
Yesi Puspita, Ghina Novarisa*) dan Novi Elian \\ Jurusan Ilmu Komunikasi FISIP Universitas Andalas \\ *) Email: ghinanovarisa90@gmail.com
}

\begin{abstract}
ABSTRAK
Kurang maksimalnya promosi yang dilakukan kampung wisata Sanjay di media sosial melatarbelakangi kegiatan ini. Promosi menggunakan media social mengharuskan pengelola melakukan up-date kegiatan sebagai sarana promosi. Selain itu, media sosial tidak muncul pada search engine, kecuali publik melakukan kunjungan ke sosial media kita. Selanjutnya promosi terbatas melalui word of mouth sehingga jangkauan publik hanya seluas jaringan tertentu saja.. Oleh sebab itu aplikasi GMB (Google my business) dari Google dapat mengatasi kelemahan dari promosi di sosial media. Aplikasi GMB dapat memperkuat promosi kampung wisata sanjai melalui pencarian google. Publik mencari dengan menggunakan kata kunci dan terkoneksi juga dengan Google maps. Kegiatan ini menggunakan metode pelatihan dan mentoring dalam menyampaikan pesan kepada kelompok pengelola dan pengusaha yang ada di kampung sanjai untuk menjadi entrepeneurs di ladang e-commerse. Beberapa usaha yang terdapat di desa Sanjai Kota Bukittinggi, tidak banyak yang telah memiliki sarana promosi secara online. Pelatihan Google My Bussiness ini diberikan untuk membekali pengusaha-pengusaha yang ada di kampung Sanjay dalam promosi dagangannya secara digital. Selain pelatihan ini juga dimanfaatkan dalam mengembangkan promosi wisata kampung Sanjay. Hasil kegiatan ini pengusaha belum maksimal dalam memanfaatkan pelatihan ini. Banyaknya kendala yang terjadi di lapangan, seperti target pelatihan yang gagap teknologi. Diperlukan upaya mentoring dengan tujuan mereka dapat melakukan upaya promosi secara mandiri.
\end{abstract}

Kata Kunci: promosi, digital marketing, google my business, wisata kampung sanjay

\section{Improving The Promotion and Management of Tourism Object through Google My Business Training in Sanjai Bukittinggi Wisata Village}

\begin{abstract}
This activity was carried out due to the lack of promotion of Sanjay village tourism through social media. Promotions using social media require managers to up-date activities as a means of promotion. Also, social media does not appear on search engines unless the public visits our social media. Furthermore, promotion is limited only to the friendships we have joined so that the public reach is only as broad as the network we have built. Therefore the GMB (google my business) application from Google can overcome the disadvantages of promotion on social media. GMB application can strengthen the promotion of the Sanjai tourist village through a Google search. Public search using keywords and also connected with google maps. This activity uses training and mentoring methods in conveying messages to management groups and entrepreneurs in the Sanjai village to become entrepreneurs in the e-commerce field. There are not many businesses in Sanjai, Bukittinggi City, not many of which have online promotion facilities. This Google My Business training is provided to equip entrepreneurs in Sanjay village to promote their merchandise digitally. In addition to this training, it was also used in developing Sanjay village tourism promotion. The result is that they are not maximal to use these applications. The many obstacles that occur in the field, such as training targets who are technologically illiterate, need mentoring efforts to carry out promotional efforts independently.
\end{abstract}

Keywords: promotion, digital marketing, google my business, sanjay village tour

Peningkatan Promosi dan Pengelola Objek Wisata Melalui Pelatihan GMB (Google My Business) Ghina Novarisa dkk. Hal. 239-249 


\section{PENDAHULUAN}

Kampung Sanjai adalah salah satu daerah di Kota Bukittinggi yang dapat menjadi destinasi wisata paket komplit. Sejak tahun 2011, Kota Bukittinggi memiliki Kampung Wisata Sanjai, dimana kampung ini menjadi lokasi tungku pertama pembuatan keripik ubi yang menjadi oleh-oleh khas Sumatera Barat yang populer dengan nama keripik sanjai. Bukittinggi telah meresmikan Kampung Wisata Sanjai ditandai dengan didirikannya gapura kampung wisata sanjai. Gambaran umum Kampung Wisata Sanjai yaitu terletak di Kelurahan Manggis Gantiang, Kecamatan Mandiangin Koto Selayan, Kota Bukittinggi, Propinsi Sumatera Barat yang merupakan salah satu kawasan tujuan wisata di Kota Bukittinggi. ditetapkan sebagai desa wisata tentu saja sanjai memiliki berbagai objek penunjang antara lain; alamnya yang indah, warganya yang ramah, udaranya yang sejuk, hamparan sawah yang masih utuh serta pemandangan alam yang ditunjang oleh penampakan dua buah gunung yakni Merapi dan Singgalang. Dengan kondisi demikian, maka Kampung Wisata Sanjai telah menjadi dan merupakan jalur perjalanan satu paket wisata yang mudah dikunjungi dalam waktu singkat diantara berbagai objek wisata yang ada di kota Bukittinggi yang sudah terkenal tidak hanya bagi wisatawan lokal juga bagi wisatawan nusantara bahkan mancanegara.

Destinasi wisata ini kurang populer di kalangan wisatawan baik lokal, nasional maupun internasional. Pada kegiatan yang dilakukan pada 2018 lalu, kegiatan melihat bahwa destinasi wisata di kampung sanjai tidak begitu terdengar gaungnya dikarenakan kurangnya branding yang dilakukan pemerintah dan masyarakat setempat, terbukti dari keripik ubi yang berasal dari kampung sanjai malah lebih terkenal dengan nama keripik sanjai dengan brand lain. Kemudian setelah membangun brand dengan baik, perlu juga dilakukan untuk menanamkan awareness kepada masyarakat luas agar branding yang tercipta dapat dimanfaatkan dengan baik.Salah satu cara yang populer dalam menanamkan brand awareness destinasi wisata adalah dengan melakukan promosi menggunakan media digital.

Saktiawan dalam Anonim (2010), mengungkapkan unsur penting dalam pengembangan desa wisata adalah keterlibatan masyarakat desa dalam setiap aspek wisata yang ada di desa tersebut. Masyarakat terlibat langsung dalam kegiatan pariwisata dalam bentuk pemberian jasa dan pelayanan yang hasilnya dapat meningkatkan pendapatan masyarakat di luar aktivitas mereka sehari-hari (Dharmawan; 2014). Sebelumnya pada tahun 2018, tim pengabdi sudah melakukan pelatihan digital marketing kepada UMKM kelompok pengelola dan pengusaha di kawasan wisata kampung sanjay. UMKM merupakan unsur penting dalam roda perekenomian daerah oleh karena itu perlu sosialisasi dan pelatihan untuk menambah pengetahuan dan keterampilan yang dimiliki oleh para pelaku UMKM agar bisa terus berkembang seiring dengan perkembangan pasar (Sari, dkk. 2019). Pelatihan yang diberikan adalah edukasi terkait pemasaran digital, dan pelatihan menggunakan media digital untuk promosi, pelatihan fotografi dan videografi. Hasilnya belum maksimal karena minimnya waktu dan sumber daya manusia yang dapat membantu pengusaha dan 
pengelola mengembangkan penggunaan media digital dalam promosi wisata kampung sanjay ini. Hal ini diakibatkan kurang maksimalnya kemampuan pemanfaatan aplikasi digital untuk media promosi kampung wisata Sanjay. Masyarakat belum maksimal berpromosi di sosial media. Pelatihan di tahun sebelumnya adalah mengenalkan sosial media yang cocok untuk melakukan pemasaran digital kampung sanjai. Namun promosi melalui sosial media masih ada kelemahaannya antara lain: Kelemahan pertama adalah promosi di sosial media harus selalu di update. setiap hari pengelola kampung sanjai harus memposting kegiatan promosi. Kedua, sosial media tidak muncul di serach engine kecuali publik melakukan kunjungan ke sosial media kita. ketiga, promosi terbatas hanya pada pertemanan yang sudah kita ikuti sehingga jangkauan publik hanya seluas jaringan yang sudah kita bangun.

Oleh sebab itu diperlukan perencanaan atau strategi dalam pemasaran UMKM tersebut. Strategi merupakan suatu pendekatan yang semua berkaitan dengan pelaksanaan gagasa, perencanaan serta eksekusi dalam aktivitas yang memiliki kurun waktu tertentu (Cangara, 2014). Perencanaan lahir dari analisis situasi yang dilakukan, dalam hal ini dapat diperoleh dari data yang lalu. Berdasarkan kegiatan yang telah dilakukan di tahun 2018, maka pengabdi tahun ini kembali melanjutkan kegiatan di kampung sanjai ini. Kendala terkait kemampuan pemanfaatan aplikasi digital kali ini menjadi fokus perhatian. Oleh karena itu, tim pengabdi memilih untuk fokus pada satu aplikasi dan memantapkannya hingga pengelola dan pengusaha dapat memanfaatkan secara maksimal. Aplikasi yang dipilih adalah google my bussines, karena fiturnya yang sudah lengkap untuk pengelola dan pengusaha mengembangkan usah. Pemanfaatan aplikasi digital google my business diharapkan mampu memberikan solusi mengatasi kendala minimnya promosi kepada publik. Oleh sebab itu aplikasi GMB (google my business) dari Google dapat mengatasi semua kelemahan dari promosi di sosial media, maka aplikasi GMB dapat memperkuat promosi kampung wisata sanjai. Promosi langsung dilakukan di pencarian google. Promosi di aplikasi google ini akan dengan mudah ditemukan ketika publik mencari dengan menggunakan kata kunci dan terkoneksi juga dengan google maps.

Melihat peluang tersebut di atas, maka pengabdi akan memberikan pelatihan pemanfaatan aplikasi gratis dari google untuk membantu kelompok pengelola kampung sanjai untuk menjadi entrepeneurs di ladang e-commerse. Oleh karena itu, peneliti termotivasi mengangkat kampung wisata ini menjadi lokasi kegiatan melanjutkan dari tahun sebelumnya dikarenakan iconic sehingga pengabdi yakin dengan potensi yang dimiliki kampung wisata sanjai. Fokus kegiatan pada pemanfaatan aplikasi GMB (google my business) yang bisa dilakukan di Kampung Wisata Sanjai ini agar bisa terus bangkit dan berkembang menjadi kampung wisata yang ideal dan sesuai dengan harapan masyarakat dan pemerintah.

Kegiatan ini dalam bentuk pelatihan penggunaan aplikasi google my business ini bertujuan untuk meningkatkan kemampuan pengelola dan pengusaha di kawasan kampung sanjay dalam mempromosikan dan mengelola kampung wisata sanjay dengan bantuan media digital yaitu google my business.

Tujuan kegiatan ini adalah sebagai berikut: 1. Memberikan pengetahuan kepada pengelola tentang promosi menggunakan media digital, 2. Memberikan pengetahuan tentang GMB (google my business) untuk meningkatkan dan memperluas 
promosi destinasi wisata kampung sanjay melalui media digital, 3. Membantu mengoperasikan GMB (google my business), 4. Meningkatkan promosi destinasi wisata kampung sanjay, 5. Meningkatkan pengunjung destinasi wisata kampung sanjay

\section{METODE}

Berdasarkan analisa permasalahan diatas, permasalahan utama yang dihadapi oleh Kampung Wisata Sanjai yaitu promosi karena tidak adanya kegiatan promosi yang pernah dilakukan oleh pengelola sehingga hanya menunggu tamu dari Dinas Pariwisata Bukittinggi dan tamu Persatuan Hotel Republik Indonesia cabang. Bukittinggi. Tidak adanya promosi yang dilakukan membuat wisatawan Kampung Wisata Sanjai menurun dari tahun ke tahun. Maraknya penggunaan teknologi dalam kehidupan masyarakat membuat pemasaran pun ikut berkembang sehingga ilmu digital marketing agar Kampung Wisata Sanjai juga bisa dipromosikan lebih meluas kepada masyarakat dengan sentuhan teknologi. Sehingga, metode yang dilakukan pada permasalahan ini yaitu pelatihan dan monitoring digital marketing yaitu google my business. Adapun yang menjadi solusi dan target luaran yang akan direncanakan dalam pemberdayaan masyarakat ini terlihat pada Tabel 1 .

Metode yang digunakan dalam kegiatan ini adalah metode pelatihan. Partisipasi mitra dalam kegiatan ini yaitu sebagai audience dalam pelatihan dan menjalankan program dari ilmu yang didapatkan selama pelatihan sehingga bisa mengembangkan Kampung Wisata Sanjai dan jika kampung ini berkembang maka akan meningkatkan perekonomian masyarakat setempat. Alat yang digunakan adalah laptop, sinyal wifi, dan hand phone. Kegiatan ini "Pelatihan GMB (Google My Business) Pada Kelompok Pengelola Kampung Wisata Sanjai Bukittinggi" dilaksanakan pada Minggu, 10 November 2019, langsung di Kota Wisata Bukittinggi.

Selanjutnya pegabdian ini melakukan metode mentoring dalam menyampaikan pesan kepada masyarakat sebagai responden. Metode mentoring sendiri merupakan metode pengembangan kemampuan dengan berbagi tips dan trik, berbagi pengalaman dan juga membagikan cara cara sukses dalam melakukan atau mengembangkan suatu hal. Pada metode mentoring biasanya melibatkan seorang pembimbing sebagai mentor. Sebelum mentoring dilakukan, terlebih dahulu para pelaku bisnis di Desa Wisata Sanjai di ajak bercerita mengenai kondisi bisnis dan upaya promosi yang dilakukan, begitu pula tentang efektifitas dan keberlanjutan Desa Wisata di Desa Sanjai yang pada kenyataan nya tidak berjalan seperti seharusnya lagi, dari bincang-bincang tersebut didapatkan fakta bahwa para pelaku usaha membutuhkan pengetahuan mengenai media promosi online untuk menunjang usaha yang mereka miliki agar terus berkembang dan dapat menarik perhatian para calon konsumen. Untuk itu diberlakukanlah metode mentoring, agar mentor dan pihak pelaku usaha dapat berbagi pengetahuan mengenai media media online untuk promosi usaha, hingga dapat menggunakan dan mendapatkan manfaat dari media tersebut. Upaya yang dilakukan selama mentoring adalah, memperkenalkan media online seperti Google My Business, mengajak pengusaha untuk menggunakan media online tersebut, dan menunjukkan manfaat dari media promosi online. 
Website. http://hilirisasi.lppm.unand.ac.id e-ISSN: 2621-7198

Tabel 1 Solusi dan Target Luaran

\begin{tabular}{|c|c|c|c|c|c|}
\hline No & Permasalahan & Solusi & $\begin{array}{l}\text { Target } \\
\text { Luaran }\end{array}$ & Capaian & Indikator Capaian \\
\hline 1 & $\begin{array}{l}\text { Kurangnya } \\
\text { pengetahuan } \\
\text { masyarakat } \\
\text { (wisatawan } \\
\text { potensial) } \\
\text { terhadap } \\
\text { destinasi wisata } \\
\text { kampung sanjay }\end{array}$ & $\begin{array}{l}\text { Melakukan } \\
\text { promosi } \\
\text { berbasis } \\
\text { teknologi dan } \\
\text { system } \\
\text { informasi } \\
\text { dengan } \\
\text { memanfaatkan } \\
\text { media digital }\end{array}$ & $\begin{array}{l}\text { - Dibuatkanya } \\
\text { platform } \\
\text { digital } \\
\text { Website } \\
\text { produk } \\
\text { - Peningkatan } \\
\text { promosi } \\
\text { destinasi } \\
\text { wisata } \\
\text { kampung } \\
\text { Sanjay }\end{array}$ & $\begin{array}{l}\text { Terbentuknya } \\
\text { platform } \\
\text { Website; } \\
\text { google my } \\
\text { business, } \\
\text { Peningkatan } \\
\text { kunjungan } \\
\text { destinasi } \\
\text { wisata } \\
\text { kampung } \\
\text { Sanjay }\end{array}$ & $\begin{array}{l}\text { Meningkatnya } \\
\text { kunjungan } \\
\text { destinasi wisata } \\
\text { kampung Sanjay }\end{array}$ \\
\hline 2 & $\begin{array}{l}\text { Minimnya } \\
\text { promosi } \\
\text { kampung wisata } \\
\text { Sanjay } \\
\text { menggunakan } \\
\text { media digital }\end{array}$ & $\begin{array}{l}\text { Memberikan } \\
\text { pelatihan dan } \\
\text { monitoring } \\
\text { untuk } \\
\text { melakukan } \\
\text { promosi } \\
\text { menggunakan } \\
\text { aplikasi google } \\
\text { my bussiness }\end{array}$ & $\begin{array}{l}\text { Pengelola dan } \\
\text { pengusaha } \\
\text { menggunakan } \\
\text { aplikasi google } \\
\text { my business } \\
\text { dalam promosi } \\
\text { kampung } \\
\text { sanjay. }\end{array}$ & $\begin{array}{l}\text { Aktifnya } \\
\text { google my } \\
\text { business dari } \\
\text { pengelola dan } \\
\text { pengusaha } \\
\text { terkait promosi } \\
\text { wisata } \\
\text { kampung } \\
\text { Sanjay }\end{array}$ & $\begin{array}{l}\text { Dapat mengelola } \\
\text { dan memperbarui } \\
\text { segala informasi } \\
\text { seputar usaha } \\
\text { kamu yang akan } \\
\text { muncul di } \\
\text { website Google } \\
\text { My Business } \\
\text { Dapat } \\
\text { menambahkan } \\
\text { berkas gambar } \\
\text { untuk memberi } \\
\text { referensi kepada } \\
\text { calon pelanggan. } \\
\text { Bisa juga } \\
\text { menggunakan } \\
\text { gambar yang } \\
\text { disimpan di } \\
\text { Google Photos } \\
\text { Dapat membuat } \\
\text { dan mengelola } \\
\text { website google } \\
\text { my bussiness } \\
\text { Dapat } \\
\text { meningkatkan } \\
\text { meningkatkan } \\
\text { ekspos usaha } \\
\text { mereka }\end{array}$ \\
\hline
\end{tabular}

Evaluasi pelaksanaan program yaitu setelah solusi dijalankan maka peneliti akan memantau selama setahun program berjalan dan akan melihat perkembangan dari Kampung Wisata Sanjai ini, sehingga, jika masih ada hal yang perlu dilakukan maka akan dilanjutkan dengan kegiatan di tahun 2020. 


\section{HASIL DAN PEMBAHASAN}

Dalam menjalankan program Desa Wisata di Kampung Wisata Sanjai ini, maka dibentuklah suatu sistem kepengurusan yang dinaungi suatu lembaga masyarakat Kelurahan Manggis Gantiang yaitu Lembaga Keswadayaan Masyarakat (LKM), berikut struktur kepengurusannya:

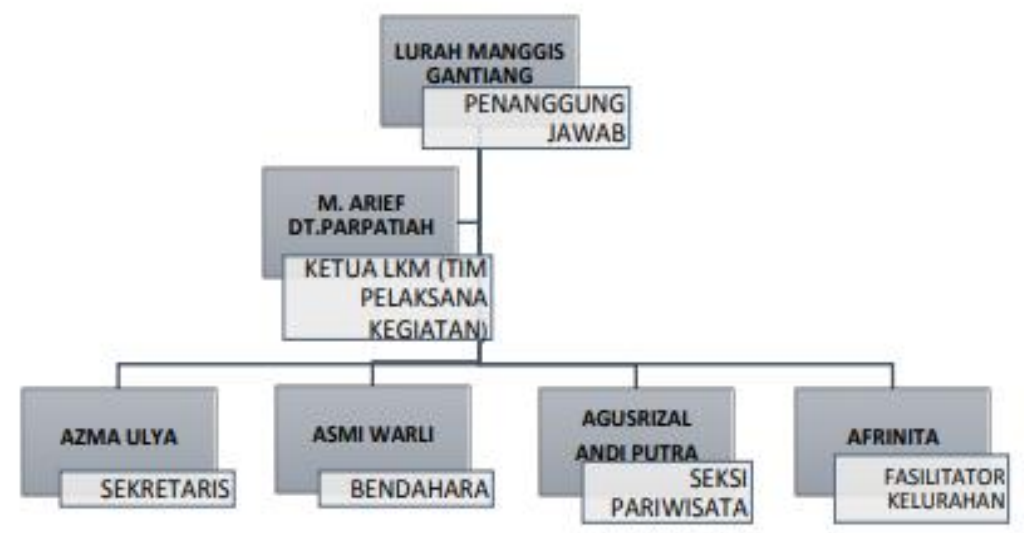

Gambar 1, Struktur Kepengurusan LKM Kelurahan Manggisa Ganting Sumber : LPJ PNPM Pariwisata Kampung Wisata Sanjai, (2012).

Selanjutnya juga dibentuk pengurusan beberapa kelompok kegiatan kepariwisataan di Kampung Wisata Sanjai berikut ini:

\begin{tabular}{|c|c|}
\hline KELOMPOK KESENIAN & •KETUA : YAZIRWAN ST.PILIHAN \\
\hline $\begin{array}{c}\text { KELOMPOK KERAINAN DAN } \\
\text { CINDERAMATA }\end{array}$ & •KETUA : ROSNI \\
\hline KELOMPOK KULINER & $\bullet$ KETUA : MELWIZAR \\
\hline KELOMPOK HOMESTAY & •KETUA : MASNIAR \\
\hline KELOMPOK TRANSPORTASI & •KETUA : JASWINATA \\
\hline KELOMPOK KEBERSIHAN & KETUA : MAIRIDAS \\
\hline
\end{tabular}

Gamabr 2. Kelompok Kegiatan Kepariwisataan di Kampung Wisata Sanjai Sumber : LPJ PNPM Pariwisata Kampung Wisata Sanjai (2012)

Dari segi manajemen, Kampung Wisata Sanjai berada dibawah naungan Lembaga Pemberdayaan Masyarakat (LPM) Kelurahan Manggis Ganting, dimana terdapat pengelolanya pada berbagai sub bidang. Kepopuleran Bukittinggi dan Jam Gadang bagi wisatawan tidak dialami serupa oleh Kampung Wisata Sanjai. Walau sudah berdiri semenjak 2011, gaungnya tidak terlalu terdengar oleh wisatawan sehingga hanya sedikit pengunjung yang datang dan dari tahun ke tahun semakin 
menurun, hal ini dibenarkan oleh ketua pengelola Kampung Wisata Sanjai (periode 2016 sampai sekarang) yaitu Bapak Sabirin Rachmat, S.Sos yang biasa disapa Inyiak Sabirin, 2) Kepala pengelola Kampung Wisata Sanjai (periode 2011 - 2016) yaitu Bapak M. Aries Dt. Parpatiah yang biasa dipanggil Inyiak Patiah, 3) Ketua Lurah Manggis Ganting yaitu Bapak M. Nuh, 4) Kabid Pariwisata dan Ekonomi Kreatif Bukittinggi yaitu Ibu Suzi Yanti, SE, MM, dan 5) General Manager Hotel Campago Periode 2011-2013 yaitu Bapak Syafroni selaku penggerak awal Kampung Wisata Sanjai.

Pada penerapannya, pelaksana yang berperan sebagai mentor mendatangi para pelaku bisnis dan pengelola Kampung Wisata Sanjai di Kota Bukittinggi. Adapun pelaku bisnis yang didatangi adalah Pabrik sekaligus pedagang Keripik Sanjai, pengelola Homestay dan juga pelaku bisnis Bordir Karancang. Disetiap kunjuangan dilakukan proses mentoring terkait penggunaan Google My Business (GMB) dan media online lainnya sebagai sarana promosi dan branding produk Desa Wisata Sanjai Kota Bukittinggi.

Mentoring ini dilakukan dengan tujuan untuk memperkenalkan dan mengajak para pebisnis juga aktif menjalankan bisnisnya secara online, sehingga bisnis dan desa wisata sanjai dapat lebih dikenal dan mudah diakses oleh banyak kalangan. Fakta yang terdapat dilapangan menunjukkan kemampuan masyarakat yang menjalankan bisnis dan mengelola Desa Wisata Sanjai tidak begitu mempuni dalam menjalankan promosi online. Berbagai kendala tersebut seperti factor usia pelaku bisnis, ketidaktahuan akan media bersangkutan dan ketidak mampuan mengelola media yang telah ada. Itulah sebabnya dilakukan mentoring untuk pengelolaan promosi bisnis dan kawasan wisata secara online melalui media Google My business dan lain lain.

Keuntungan dari adanya media promosi online seperti Google My Business, Instagram, Facebook, dan lain-lain yaitu luasnya cakupan promosi yang dapat menggapai hampir seluruh pihak. Hal ini selaras dengan kehidupan digital yang memang sudah dijalankan oleh sebagian besar masyarakat. Kebiasaan mencari segala sesuatu memalui bantuan Google juga menuntut kesanggupan para pemilik bisnis dan kawasan wisata untuk menginformasikan keberadaan mereka melalui media online. Dengan begitu, jika nantinya para calon wisatawan yang sedang mencari oleh-oleh atau kawasan wisata kuliner dan budaya dapat mengakses keberadaan Desa Wisata Sanjai ini dengan mudah.

Pada kegiatan "Pelatihan GMB (Google My Business) Pada Kelompok Pengelola Kampung Wisata Sanjai" didatangi 3 jenis usaha rumahan masyarakat di Desa Sanjai. Usaha tersebut terdiri dari usaha kerupuk sanjai (pabrikan sekaligus pedagang), usaha bordir karancang, dan juga usaha jasa homestay yang merupakan pendukung program Desa Wisata Sanjai. Pada ketiga jenis usaha tersebut, pelaksana kegiatan terlebih dahulu melakukan pendekatan dan wawancara mengenai efektivitas promosi usaha serta efektivitas program Desa Wisata pada Desa Sanjai. Tentunya setelah wawancara, dilakukan mentoring penggunaan media online sebagai sarana promosi usaha. Berikut beberapa kondisi dari pengelola dan pengusaha wisata kampung sanjay:

\section{Usaha Sanjai Erly}


Usaha sanjai Erly merupakan usaha pabrikan, pedagang dan penyalur kerupuk sanjai ke pasar-pasar Kota Bukittinggi. Baik pabrik, maupun toko sanjai Erly terbilang sederhana. Ibu Erly selaku pemilik usaha sanjai mengatakan bahwa, ia hanya memiliki sarana dagang konvensional seperti saat sekarang ini. Tanpa ada sarana promosi dan marketing online. Tahun sebelumnya memang ada pihak yang membantu promosi online usaha Erly, namun tidak dapat dilanjutkan karena tidak ada yang data mengelola dari pihak Usaha Erly. Baik mengelola media online usahanya, maupun penerus untuk usaha sanjai Erly.

Selain itu, menurut Erly, program Desa Wisata di Sanjai sendiri tidak lagi berjalan dengan efektif. Tidak ada kegiatan khusus yang dilakukan untuk tetap menjalankan program ini. Untuk itu pelaksana kegiatan mengajak Ibu Erly untuk mengenal Google My Business dan media online lainnya untuk mempromosikan usaha Erly secara Online. Dengan adanya Google My Business usaha Sanjai Ibu Erly ini akan sangat membantu calon konsumen mengetahui usaha Erly ini, sehingga, promosi semakin luas dan penghasilan pun akan semakin melonjak. Selain hal itu, pihak wisatawan juga akan semakin mengenal keberadaan Desa Sanjai, sebagai daerah penghasil Kerupuk Sanjai ini. Kemudian juga disampaikan bagaimana mengemas promosi usaha melalui media social Instagram dengan memperlihatkan contoh Online Shop makanan yang sudah berjalan efektif.

\section{Usaha Sanjai Minang Maimbau}

Usaha sanjai minang maimbau merupakan pabrikan kerupuk sanjai sekaligus pedagang dan penyalur kerupuk sanjai ke beberapa pedagang di pasar-pasar kota Bukittinggi. Perusahaan ini sendiri dapat dikatakan cukup besar dibandingkan dengan usaha Sanjai lainnya. Dari wawancara yang dilakukan dengan Ibu Esmayenin(karyawan) mengatakan Sanjai Minang Maimbau, Sanjai Minang Maimbau sendiri telah memiliki akun social media berupa facebook yag dikelola oleh anak pemilik usaha Sanjai Minang Maimbau. Menurut beliau, banyak pembeli dari luar daerah yang datang berkunjung ke Pabrik Minang Maimbau untuk berbelanja oleh oleh karena adanya promosi memalui akun Facebook ini, seperti calon pembeli dari Dumai, Aceh dan lain sebagainya. Meski belum menggunakan Google My Business yang sifatnya lebih Universal, promosi melalui fecebook cukup efektif untuk menarik perhatian calon konsumen terutama dari luar daerah.

Hal ini juga tentunya turut mendukung program Desa Wisata di desa Sanjai sendiri. Selain membeli oleh-oleh, para konsumen berwisata melihat proses dan tungku produksi sanjai. Meskipun kenyataannya, program desa wisata Sanjai sendiri tidak jelas dan tidak begitu efektif kelanjutannya.

\section{Usaha Homestay Erly}

Usaha Homestay Erly, juga dimiliki oleh pemilik Usaha Kerupuk Sanjai Erly. Homestay Erly tidak lagi pernah dioperasikan karena tidak ada yang mengelola dan dapat dikatakan tidak banyak calon wisatawan yang mengetahui keberadaan beberapa Homestay di Daerah Desa Wisata Sanjai ini. Selain tidak adanya promosi konvensional lanjutan dari masyarakat maupun pemerintah, juga tidak terdapat satupun sarana 
promosi secara online yang dimiliki oleh para pemilik Homestay.dari sekitar 4-5 homestay yang ditemui, hanya satu yang menurut warga tetap aktif menjalankan bisnis Homestaynya

Pelaksanaan kegiatan ini memperkenalkan Google My Business kepada pemilik Usaha Homestay, dimana pengelolaan akun GMB ini tidak terlalu rumit, tidak membutuhkan perbaruan informasi yan begitu berarti, namun dapat berperan sangat banyak untuk mempromosikan keberadaan homestay-homestay yang ada di Desa Wisata Sanjai

\section{Usaha Bordir dan Karancang Rosni}

Usaha bordir dan karancang merupakan salah satu usaha kerajinan khas Kota Bukittinggi yang juga beberapa pabrikannya berada di Desa Wisata Sanjai. Sebenanya, pabrikan border dan karancang khas bukittinggi ini dapat menjadi destinasi wisata dan oleh oleh yang sangat baik untuk disajikan kepada wisatawan,selain membeli, para wisatawan dapat mengetahui proses pembuatan Bordir Karancang ini.

Namun, tidak banyak yang mengetahui keberadaan pabrikan border di desa Sanjai ini, sama seperti sebelumnya, tidak ada nya sarana promosi yang mumpuni untuk wisatawan dapat berkunjung ke usaha Bordir dan Desa Wisata Sanjai, meski sebelumnya ada pihak yang membantu membuat media online sebagai sarana promosi tanpa kelanjutan Menurut pemilik pabrikan bordir, kendala terbesar dari usaha ini adalah modal yang cukup besar

Untuk itu, mentor kembali memperkenalkan dan mengajak pemilik usaha untuk mempromosikan usahanya melalui Google My Business dan juga media sosil lainnya. Tentu dengan upaya promosi online ini, dapat meningkatkan ketahuan (awereness) calon konsumen/wisatawan mengenai adanya usaha Pabrikan Bordir dan Karancang khas Bukittinggi di Desa Wisata Sanjai, sehingga meningkatkan daya beli konsumen.

Berikut adalah hasil dari pelatihan dan monitoring dalam bentuk penjabaran luaran dan capaian yang diperoleh dari keempat UKM yang mengikuti pelatihan GMB (google my Bussiness) terlihat pada Tabel 2. 
Website. http://hilirisasi.lppm.unand.ac.id e-ISSN: 2621-7198

Table 2. Hasil Capaian Pelatihan dan Monitoring

\begin{tabular}{|c|c|c|}
\hline Nama Usaha & Capaianl Luaran & Indikator Capian \\
\hline Usaha sanjai Erly & $\begin{array}{l}\text { platform digital Website } \\
\text { produk usaha sanjay } \\
\text { - Meningkatnya promosi } \\
\text { produk usaha sanjay } \\
\text { - Pengusaha menggunakan } \\
\text { aplikasi google my business } \\
\text { dalam promosi usaha sanjay. }\end{array}$ & $\begin{array}{l}\text { - Usaha ini sudah memiliki } \\
\text { platform website google my } \\
\text { bussiness usaha sanjay Erly } \\
\text { - Usaha ini sudah bisa di cetek } \\
\text { di mesin pencarian google, } \\
\text { - Penggunaan GMB masih } \\
\text { bergantung pada pelatihan, } \\
\text { belum dilakukan secara } \\
\text { mandiri }\end{array}$ \\
\hline Usaha Sanjai Minang Maimbau & $\begin{array}{l}\text { - platform digital Website } \\
\text { produk usaha sanjay } \\
\text { - Meningkatnya promosi } \\
\text { produk usaha sanjay } \\
\text { - Pengusaha menggunakan } \\
\text { aplikasi google my business } \\
\text { dalam promosi usaha sanjay. }\end{array}$ & $\begin{array}{l}\text { Usaha ini tidak memiliki } \\
\text { akun google my bussines tapi } \\
\text { menggunakan sosial media } \\
\text { lainnya sebagai media } \\
\text { promosi } \\
\quad \text { Penggunaan sosial media } \\
\text { cukup membantu dalam } \\
\text { proses promosi usaha sanjai } \\
\text { Minang Maimbau }\end{array}$ \\
\hline Usaha Homestay Erly & $\begin{array}{l}\text { - platform digital Website } \\
\text { produk usaha sanjay } \\
\text { - Meningkatnya promosi } \\
\text { produk usaha sanjay } \\
\text { - Pengusaha menggunakan } \\
\text { aplikasi google my business } \\
\text { dalam promosi usaha sanjay. }\end{array}$ & $\begin{array}{l}\text { - Usaha ini sudah memiliki } \\
\text { platform website google my } \\
\text { bussiness usaha homestay } \\
\text { Erly dan media sosial lainnya } \\
\text { - Usaha ini sudah bisa di detek } \\
\text { di mesin pencarian google, } \\
\text { - Penggunaan GMB dilakukan } \\
\text { secara cukup mandiri }\end{array}$ \\
\hline $\begin{array}{l}\text { Usaha Bordir dan Karancang } \\
\text { Rosni }\end{array}$ & $\begin{array}{l}\text { - platform digital Website } \\
\text { produk usaha sanjay } \\
\text { - Meningkatnya promosi } \\
\text { produk usaha sanjay } \\
\text { - Pengusaha menggunakan } \\
\text { aplikasi google my business } \\
\text { dalam promosi usaha sanjay. }\end{array}$ & $\begin{array}{l}\text { - Usaha ini sudah memiliki } \\
\text { platform website google my } \\
\text { bussiness usaha sanjay Erly } \\
\text { - Usaha ini sudah bisa di cetek } \\
\text { di mesin pencarian google, } \\
\text { - Penggunaan GMBtidak aktif } \\
\text { dan tidak mandiri }\end{array}$ \\
\hline
\end{tabular}

\section{KESIMPULAN DAN SARAN}

Dari beberapa usaha yang terdapat di desa Sanjai Kota Bukittinggi, tidak banyak yang telah memiliki sarana promosi secara online. Bahkan upaya promosi secara konvensional juga sangat minim. Untuk itu, agar keberlanjutan usaha dan promosi Desa Sanjai lebih dikenal luas oleh masyarakat nasional maupun internasional, dibutuhkanlah sarana promosi secara online. Yang mana, sarana promosi online ini bersifat lebih universal, mudah, dan tidak membutuhkan bayak biaya.

Upaya promosi secara online ini, sudah dilakukan oleh pengelola dan pengusaha yang diberikan pelatihan dan monitoring terkait penggunaan aplikasi google my business. Namun demikian penggunaan ini belum maksimal karena ketergantungan 
pengelola dan pengusaha pada pelatihan dan monitoring ini, tidk dapat dilakukan secara mandiri, Perlu adanya upaya mentoring terhadap adanya media promosi bisnis secara online ini kepada masyarakat pelaku bisnis di Desa Sanjai, dengan tujuan mereka dapat melakukan upaya promosi secara mandiri dan kekinian melalui media online, yang nantinya juga akan sangat mudah di akses oleh calon wisatawan dan calon pembeli.

Kegiatan ini mengenai "Pelatihan GMB (Google My Business) Pada Kelompok Pengelola Kampung Wisata Sanjai Bukittinggi” tentunya hanya merupakan langkah awal yang dapat dilakukan untuk tetap mempopulerkan keberadaan Desa Wisata Sanjai dan segudang usaha masyarakat di dalamnya. Untuk selanjutnya, dibutuhkan perhatian dan pelatihan khusus untuk masyarakat setempat akan penggunaan media promosi online baik Google My Business maupun media online lainnya. Tentu diharapkan kepada pihak berkepentingan terkait, seperti pemerintah Kota dan masyarakat sekitar, untuk meneruskan upaya promosi keberadaan Desa Wisata Sanjai di Kota Bukittinggi .

\section{DAFTAR PUSTAKA}

Cangara, dan Hafied. 2014. Perencanaan dan Strategi Komunikasi. PT. Raja Grafindo Persada, Jakarta.

Lupiyoadi, Rambat, dan A. Hamdani. 2006. Manajemen Pemasaran Jasa, Salemba Empat, Jakarta.

Dharmawan, I.M. Adi. I.M. Srjana, dan I.D.A.S. Yudhari. 2014. Strategi pengembangan desa wisata di Desa Belimbing Kecamatan Pupuan Kabupaten Tabanan. E-Jurnal Agribisnis dan Agrowisata, 3 (1), Januari 2014 retrieved: http://ojs.unud.ac.id/index.php/JAA

Sari, D. K., Darlis, V., dan Meidilisa, V. (2019). Penerapan mobile marketing dan perbaikan packaging pada UMKM Sumatera Barat tepung dan olahan sala Uni Jamila. Jurnal Hilirisasi IPTEKS, 2(3b): 305-314.

Syah, Firman. 2017. Strategi Mengembangkan Desa Wisata. Unisban: Prosiding Seminar Nasional Multi Disiplin Ilmu \&Call For Papers Unisbank Ke-3 ISBN:9-789-7936-499-93 retrieved: https://neliti.com

Vahlia, I., dan N. Lelawati. 2019. Pelatihan e-commerce dan manajemen keuangan sebagai langkah meningkatkan pendapatan pada keripik pisang arjuna. Jurnal Hilirisasi IPTEKS, 2(4. b): 509-518. 